\title{
Characterization and photocatalytic activities of nanosized titanium dioxide thin films
}

\author{
${ }^{1 *}$ F. Mastali Khan Tehrani; ${ }^{2}$ M. Rashidzadeh; ${ }^{3}$ A. Nemati; ${ }^{2}$ A. Irandoukht; ${ }^{2}$ B. Faridnia \\ ${ }^{1}$ Department of Materials Engineering, Science and Research Branch Islamic Azad University, Tehran ,Iran \\ ${ }^{2}$ Catalysis Research Center, Research Institute of Petroleum Industry, Tehran, Iran \\ ${ }^{3}$ Department of Materials Science and Engineering, Sharif Univer sity of Technology, Tehran, Iran \\ Received 24 August 2010; revised 5 January 2011; accepted 20 February 2011; available online 1 June 2011
}

\begin{abstract}
Thin films of titanium dioxide with high surface area are prepared by sol-gel dip-coating technique. In this regards, Titania nano sols with high photocatalytic activity were prepared by dissolving titanium alkoxide in alcohol and water under acidic conditions. Photocatalytic activities of titanium dioxide thin films were measured in the presence of methylene blue. Microstructure and photocatalytic activity of the films, nanopowders and titanium dioxide sols were investigated using X-ray diffraction, scanning electron microscopy, specific surface area, zeta sizer and ultraviolet-visible spectrometry techniques. Particle size analysis of sols showed that the mean particle sizes were 15 to $128 \mathrm{~nm}$. X-ray diffraction analyses revealed that anatase crystal structure was produced with crystallite size below $11 \mathrm{~nm}$. Increasing mass percent of anatase phase and specific surface area, enhance the photocatalytic activity. Scanning electron microscopy images showed that the addition of methylcellulose as a dispersant, not only produced rough texture in the thin film, but also enhanced photocatalytic activity. The thin films prepared by using nitric acid as a stabilizer, revealed higher photocatalytic activity, surface area and sol stability and these data were more than those prepared with acetic acid.
\end{abstract}

Keywords: Dip-coating; Environmental purification; Morphology; Stabilizer

\section{INTRODUCTION}

Titanium dioxide $\left(\mathrm{TiO}_{2}\right)$ is the most promising semiconductor photocatalyst, which has been extensively studied for environmental purification applications, due to its good characteristic of powerful oxidation strength, chemical stability and nontoxicity. It is especially interesting to support $\mathrm{TiO}_{2}$ on inert substrates for waste water and indoor atmosphere remediation (Negishi and Takeuchi, 2001; Hidalgo et al., 2004; Jing-Sheng et al., 2006; Wang et al., 2007). Recently, Titania nano particles proved to be very effective in degrading organic pollutants in environment and petrochemical industry (keshmiri et al., 2004; Sankapal et al., 2005; Babel and Opiso, 2007; Samarghandi et al., 2007; Gan et al., 2008; Giri et al., 2010; Hussain and Siddaqa, 2011). Volatile organic compounds (VOCs) are triggering serious

\footnotetext{
\* *Corresponding Author Email: farahnaz.tehrani@yahoo.com Tel: +9821 8803 6018; Fax: +9821 44739709
}

environmental problems such as alcohols, mercaptans, ketones, ethers and dye dissolved in the solution, among which Methylene blue (MB) has been used as much as dye (Wang et al., 1998; Mills et al., 2003). The effectiveness of $\mathrm{TiO}_{2}$ photocatalyst in aqueous system is evaluated by degradation rate of an organic model molecule such as MB because it has less absorption at the absorption edge $(\sim 380 \mathrm{~nm})$ of anatase phase and proved to be a relatively strong and stable molecule under UV irradiation (Wold, 1993; Habibi et al., 2007; Medina-Valtierra et al., 2007; Yogi et al., 2008). $\mathrm{TiO}_{2}$ exists in three principal crystallographic forms: anatase, brookite and rutile, however only the anatase form is photocatalytic active (Yang et al., 2004; Collins-Martnez et al., 2007). Most of the photocatalysts have been used as a fine powder form which has strong oxidative power of photogenerated holes on the surface. However, the fine powder form has several problems as follows: 
1) Separation of the catalyst from the suspension after the reaction is difficult.

2) The suspended particles tend to aggregate at high concentrations.

3) The amount applied is small and limited.

When the catalyst is coated on some supports, detachment from the supports easily occurs in the liquid phase (Verma et al., 2005; Cernigoj et al., 2006b; Ming-Fang et al., 2006; Zhu et al., 2008; 2009). Many techniques have been developed for immobilizing $\mathrm{TiO}_{2}$ catalyst on solid substrates, for example, dip coating from suspension and spray coating, sputtering, solgel-related methods, electrophoretic deposition and atomic layer deposition of $\mathrm{TiO}_{2}$ thin films. Among them the relatively simple sol-gel method is the most widely used (Guo et al., 2005; Cernigoj et al., 2006a; Mahshid et al., 2007; Vilhunen et al., 2008; Vilhunen and Sillanpaa., 2009). The sol-gel technique has attracted more attention due to low process cost, low temperature of heat treatment and wide possibility to vary film properties by changing the composition of the solution. The morphology, particle size and crystalline phase of the films, as well as their porosity and surface area, are important factors to influence catalytic activity (Verma et al., 2005; Cernigoj et al., 2006b; Gan et al., 2008).

Photocatalytic activity of titanium is strongly dependent on its phase structure, crystallite size, specific surface areas, and pore structure. It seems of the high crystallinty of anatase phase extends the recombination rate of the electron and hole, hence, strong reducing and oxidizing power of the photocatalyst. In addition, the high surface area facilitates adsorption of the target molecules on to the surface of the catalyst and accelerates the photocatalytic reaction (Kana and Wongnawa, 2008).

The objective of this study is the investigations on processing and structural characteristics of high photocatalytic activity $\mathrm{TiO}_{2}$ thin films with high surface area deposited on glass substrates through the dipcoating method. The photocatalytic activities of $\mathrm{TiO}_{2}$

Table 1: Synthesis condition of Sols

\begin{tabular}{cccc}
\hline Sol sample & $\mathrm{CH}_{3} \mathrm{COOH}(\mathrm{Mol})$ & $\mathrm{HNO}_{3}(\mathrm{Mol})$ & $\mathrm{MC}(\mathrm{Wt} \%)$ \\
\hline Sol.1 & 0.0068 & - & 2 \\
Sol.2 & - & 0.0068 & 2 \\
Sol.3 & 0.0068 & - & - \\
Sol.4 & - & 0.0068 & - \\
\hline
\end{tabular}

thin films have been studied by addition two different kinds of stabilizers in the presence of dispersant.

This research was carried out in Research Institute of Petroleum Industry in 2010.

\section{MATERIALS AND METHODS}

\section{Experimental procedure}

The thin films of $\mathrm{TiO}_{2}$ were deposited by dip-coating sols which were prepared through a sol-gel route. The substrate used were pieces of soda lime glass plates $(76 \mathrm{~mm} \times 26 \mathrm{~mm} \times 1 \mathrm{~mm})$ purchased from Corning Inc. The substrates were cleaned for $2 \mathrm{~h}$ in an ultrasound bath (Model Starsonic 60) with ethanol and then dried in an oven at $80^{\circ} \mathrm{C}$ for $15 \mathrm{~min}$. In order to coat supports with titanium dioxide, titania sol prepared as follows: $30 \mathrm{~mL}$ of titanium (IV) iso-propoxide (TTIP) (Merck, 98 $\%$ ) was dissolved in $10 \mathrm{ml}$ of iso-propanol (Merck, 99.5 $\%$ ) and proper amount of doubled distillated water. Then the prepared solution stirred by mechanical impeller ( $800 \mathrm{rpm}$ ) for $8 \mathrm{~h}$.

After complete mixing of the solution, nitric acid $\left(\mathrm{HNO}_{3}\right)(\mathrm{Merck}, 65 \%)$ or acetic $\operatorname{acid}\left(\mathrm{CH}_{3} \mathrm{COOH}\right)($ Merck, $95 \%$ ) were added as stabilizers and Methylcellulose (MC) (Merck, $2 \mathrm{Wt} \%$ ) was used as a dispersant in preparation of samples.

The sols were deposited on glass plates while the temperature was kept at $25^{\circ} \mathrm{C}$ during the deposition and the operation was repeated several times with content of $0.3 \mathrm{mg} \mathrm{TiO}$ per $\mathrm{g}$ of plates. Then, the dipcoated plates were calcined at $350{ }^{\circ} \mathrm{C}$ for $1 \mathrm{~h}$ with a heating rate of $2{ }^{\circ} \mathrm{C} / \mathrm{min}$. Table 1 shows the synthesis conditions of prepared samples. It is worth mentioning that the sols which named Sol.1, Sol.2, Sol.3 and Sol.4 after calcination process are called CAT.1, CAT.2, CAT. 3 and CAT.4, respectively in Table 2.

\section{Evaluation of photocatalytic activity}

The photocatalytic activity of the thin films was evaluated by decomposition of Methylene blue (20 ppm) versus $50 \mathrm{ppm}$ of $\mathrm{TiO}_{2}$ photocatalyst. The photoreactor consisted of a cylindrical glass reactor with a high pressure mercury $400 \mathrm{w}$ lamp located in front of vessel.

The variation of $\mathrm{MB}$ absorbance through $1 \mathrm{~h}$ was measured at $\lambda_{\max }=665 \mathrm{~nm}$ using a Du series $500 \mathrm{UV}$ Vis spectrophotometer. The degradation of $\mathrm{MB}$ values were calculated as follows:

Degradation $(\%)=\left[\left(\mathrm{C}_{\mathrm{o}}-\mathrm{C}\right) / \mathrm{C}_{\mathrm{o}}\right]_{\times} 100$ 
Where $\mathrm{C}_{\mathrm{o}}$ and $\mathrm{C}$ are initial and ultimate concentrations of MB respectively (Akyol et al., 2004; Tobaldi et al., 2008).

\section{Characterization techniques}

The crystal structure of $\mathrm{TiO}_{2}$ coatings was identified by XRD (XRD, Philips PW 1840; Cuk $\alpha$ radiation at 40kV and $200 \mathrm{~mA}$ ). Preferred orientations were determined by comparing their relative intensities with those reported in the Joint committee on powder diffraction standards (JCPDS) cards (Ming-Fang et al., 2006). The phase content of samples can be calculated from the integrated intensities of anatase (101) peak as:

$$
W_{A}=\frac{K_{A} A_{A}}{K_{A} A_{A}+A_{R}+K_{B} A_{B}}
$$

Where $\mathrm{W}$ represents the mass fraction of anatase and $A_{A}, A_{B}, A_{R}$, are the integrated intensities of the anatase (101), brookite (121) and rutile (110) peaks and $\mathrm{K}_{\mathrm{A}}$ and $\mathrm{K}_{\mathrm{B}}$ are two coefficients and their values are 0.886 and 2.721, respectively. With Eq. 3, the phase contents in any $\mathrm{TiO}_{2}$ samples can be calculated (JCPDS Powder Diffraction File, Card 21-1272, 21-1276, 29-1360).

The average crystallite size of anatase was determined according to the Scherrer equation using a FWHM data of each phase (Keshmiri et al., 2004; Sankapal et al., 2005; Hosseini et al., 2007; Sreemany and Sen, 2007). The Brunaur-Emmett-Teller (BET) surface of the powders was measured by $\mathrm{N}_{2}$ gas adsorptions-desorption at 77K using a Quantasorb BET surface area analyzer.
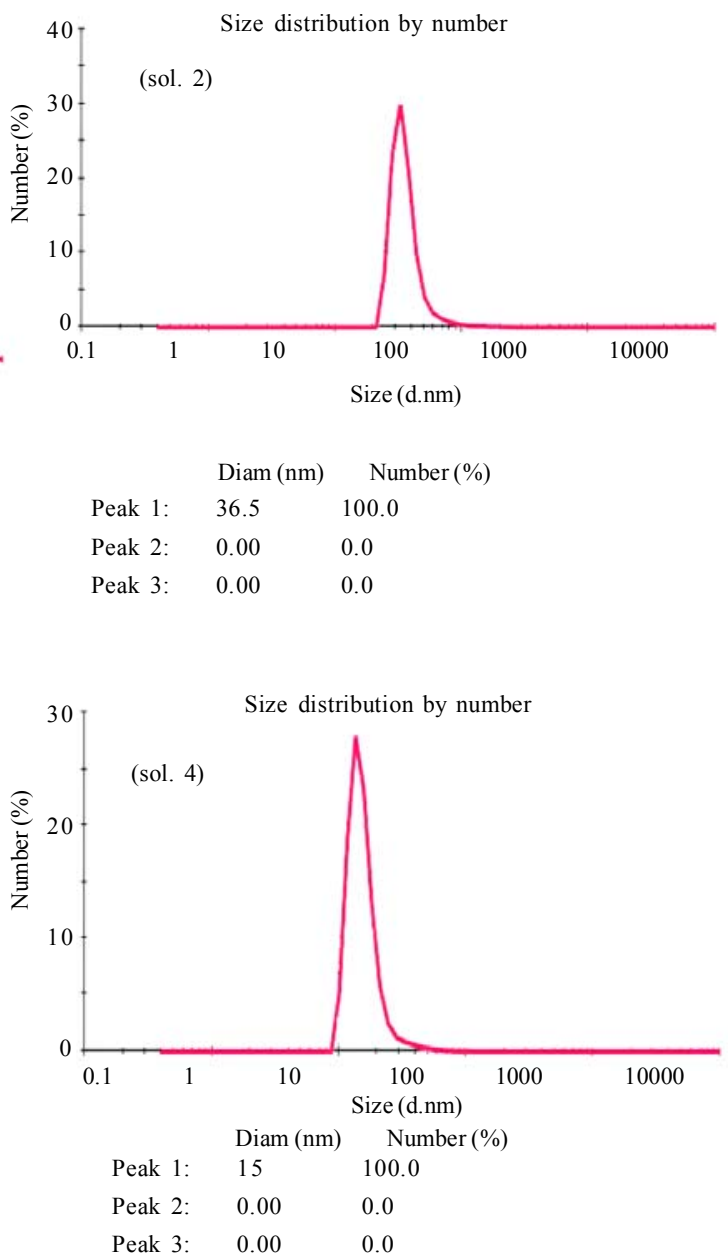
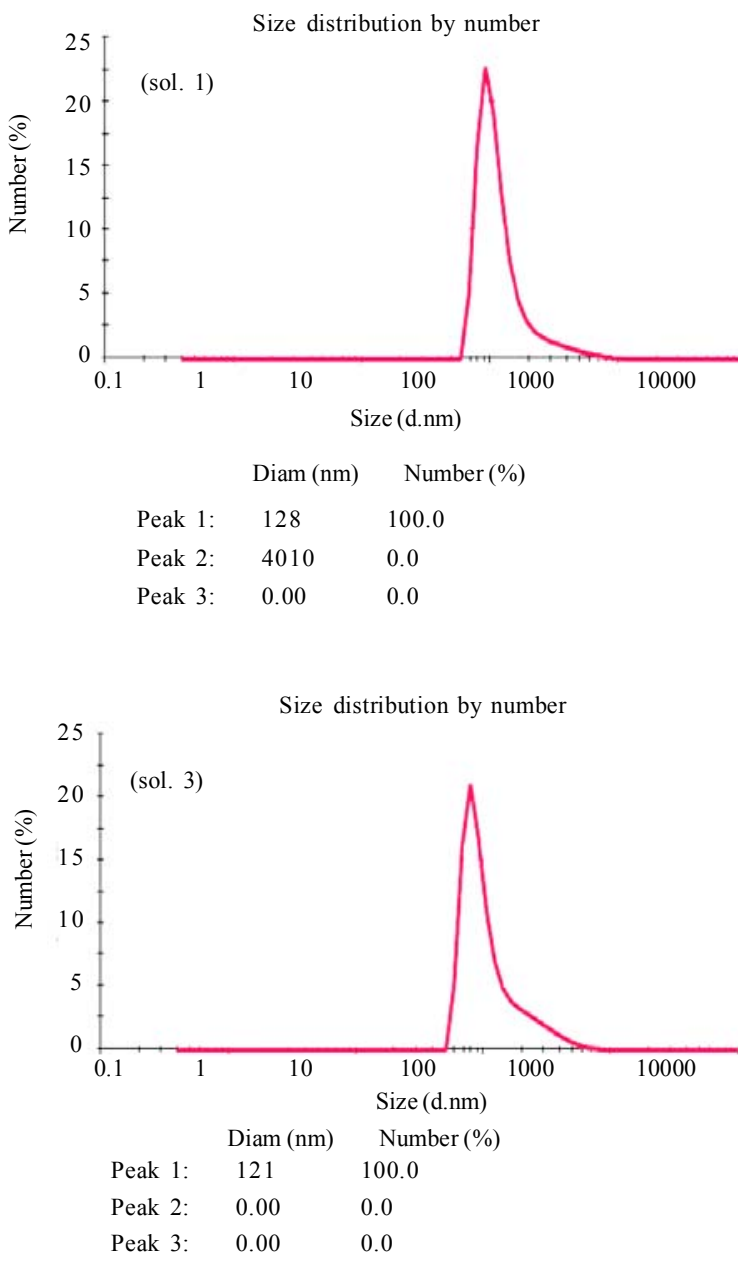

Peak 2: $4010 \quad 0.0$

Peak 3: $0.00 \quad 0.0$

Fig.1: Size distribution and mean particle size of Sol.1-Sol.4 


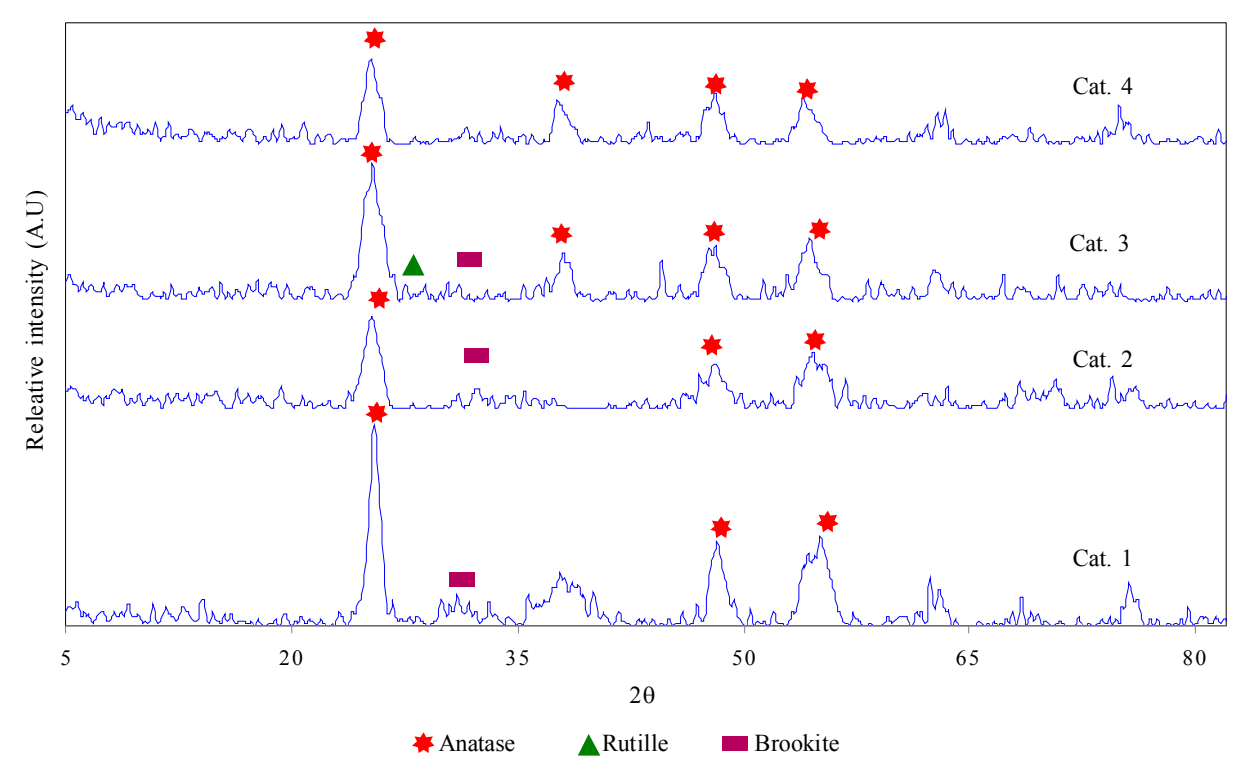

Fig. 2: XRD patterns of prepared $\mathrm{TiO}_{2}$ nano films

Table 2: Characterization data of the $\mathrm{TiO}_{2}$ thin films

\begin{tabular}{|c|c|c|c|c|}
\hline Analysis & CAT.1 & CAT.2 & CAT. 3 & CAT.4 \\
\hline Anatase phase (\%) & 69 & 80 & 74 & 89 \\
\hline${ }^{*} \mathrm{~d}(\mathrm{~nm})$ & 11 & 7.1 & 7.4 & 6 \\
\hline
\end{tabular}

"Calculated from Scherrer equation for anatase phase

The particle sizes of prepared sols were analyzed using a Malvern particle size analyzer, $24 \mathrm{~h}$ after preparation. The samples must be diluted in water and they were also sonicated for $2 \mathrm{~min}$. Microstructure of the thin films was observed by Scanning electron microscope (SEM) Philips XLC30 at a voltage of $30 \mathrm{kV}$ (sputtered by gold).

\section{RESULTS AND DISCUSSION}

Stability of $\mathrm{TiO}_{2}$ suspension

Fig. 1 shows that type of acid and presence of $\mathrm{MC}$ had a huge impact on stability of the sols after some months and it implied that Sol.2 with nucleophilic group such as $\mathrm{NO}_{3}^{-}$was more stable than Sol.3. However, $\mathrm{CH}_{3} \mathrm{COO}^{-}$group cannot counteracts the particle agglomeration induces by natural attractive Vander Waals forces and after passing time the whole sol was precipitated. Therefore, Sol.2 and Sol.4 which contained $\mathrm{HNO}_{3}$ as an acid catalyst demonstrate diminutive size distributions (Fig. 1).
On the other hand, addition of massive component such as MC enhanced the sol density, so, Sol.1 and Sol.3 with poorly defined size distributions precipitated after short time. That explains that $\mathrm{HNO}_{3}$ prevents aggregation strongly (Yu et al., 2003).

Physical properties of synthesized $\mathrm{TiO}_{2}$ powders

Fig. 2 shows the XRD patterns of the CAT.1-4 of thin films after calcination at $350^{\circ} \mathrm{C}$. Table 2 shows the effects of $\mathrm{HNO}_{3}, \mathrm{CH}_{3} \mathrm{COOH}$ as hydrolysis catalysts on phase structure and average crystalline size of $\mathrm{TiO}_{2}$ thin films. As it is cleared, mass percent of anatase phase of theses catalysts has altered in order of CAT. $4>$ CAT. $2>$ CAT. $3>$ CAT. 1 which has implied the role of acids. It is obvious that $\mathrm{HNO}_{3}$ is a much stronger acid catalyst than $\mathrm{CH}_{3} \mathrm{COOH}$ to crystallize anatase phase. In order to literature (Yu et al., 2003) acid concentration is a dominant factor in formation of anatase phase, because $\mathrm{H}^{+}$ions rearrange the amorphous aggregates to form a crystalline anatase.

These results are in good agreement with that of other researches (Terabe et al., 1994) who claimed that the anatase phase is stable in acidic solutions. Furthermore, the calculated average crystallite size of prepared sols proved the fact that the presence of $\mathrm{H}^{+}$can affect the average crystallite size. According to the order of $\mathrm{pH}$ value of the sols CAT.1>CAT.3> 

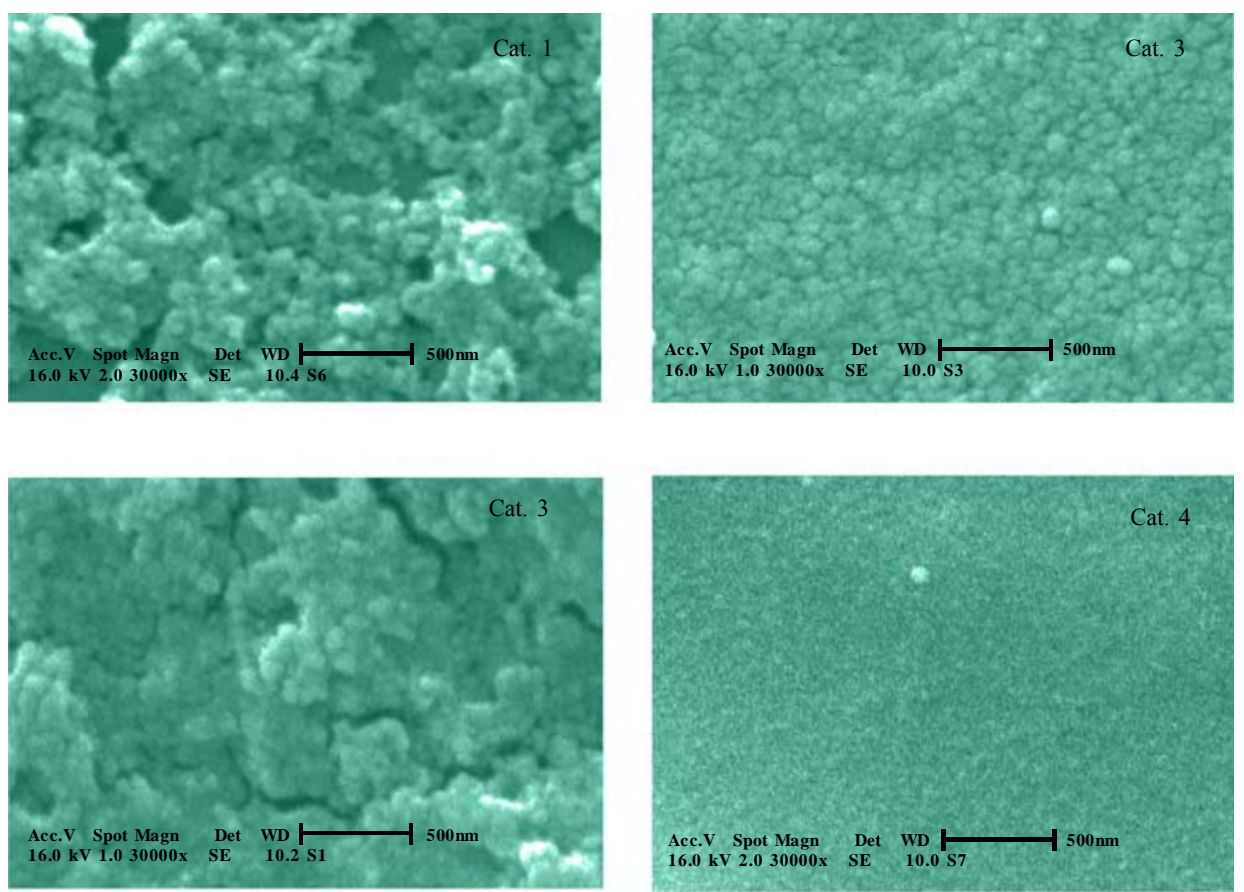

Fig.3: SEM images of the $\mathrm{TiO}_{2}$ thin films deposited from sol on glass substrates with 2 dipping-heating cycles
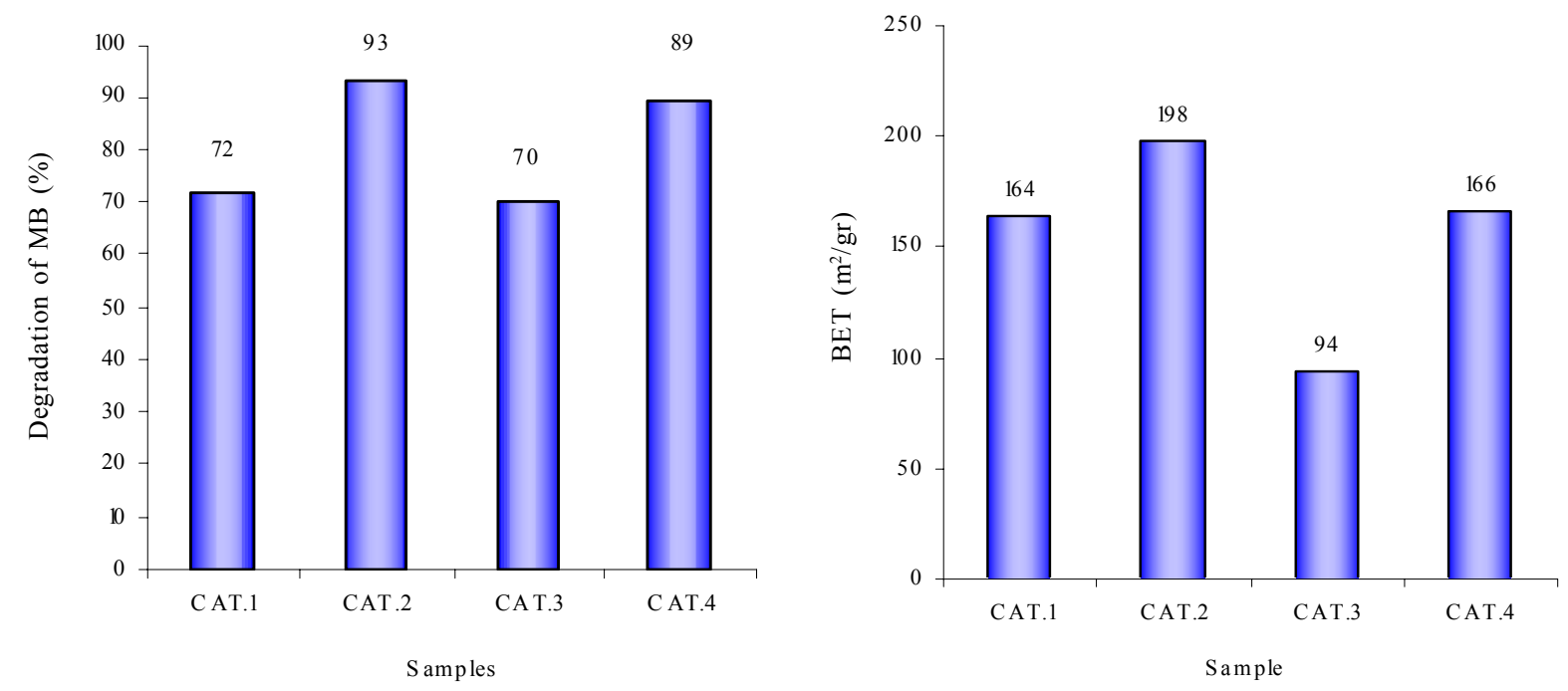

Fig. 4: a) Degradation of MB after 60 min, (b) Specific Surface area of CAT.1-CAT.4

CAT.2 $>$ CAT.4, it is obvious that $\mathrm{TiO}_{2}$ particle sizes growing with enhancing of $\mathrm{pH}$ value. These results are similar to those observed by other researches (Hu and Yuan, 2005) who pointed out that a single crystallite of $\mathrm{TiO}_{2}$ is appeared since the acidity of the solution was high enough $(\mathrm{pH}=1.2)$ and agglomeration will increase as acidity of the solutions decreased.

\section{SEM studies}

Fig. 3 Shows the SEM images of nano $\mathrm{TiO}_{2}$ films of 
CAT.1-4. As it can be seen, CAT.4 contains nonagglomerated spherical morphology, however the rest of the samples have incoherent surfaces which is due to their synthesis conditions.

CAT.4 among all the samples has the best quality as a coated film because $\mathrm{HNO}_{3}$ is strong enough to reduce hydrolysis and condensation speed of the sols. Hence, CAT. 4 appears as a unity structure but in CAT.3, $\mathrm{CH}_{3} \mathrm{COOH}$ caused phase separation in the sols and produced cracked and rough texture in films. Although these results are in good agreement with $\mathrm{Bu}$ et al. (2005) who found that $\mathrm{CH}_{3} \mathrm{COOH}$ origins phase separation but in CAT.3 it hasn't been marked any isolated islands similar to their results. This may be attributed to the different preparation route of the sol especially the presence of iso-propanol as a solvent. In fact, side branches in iso-propanol provide the ability to adjust opposite charges efficiently, in a way that isolated islands have not appeared in CAT.3. The presence of MC displays rough texture and granular microstructure in CAT.4 and CAT.2, respectively (Fig. 3).

This may be ascribed by vanishing MC after calcinations. Moreover, Cernigoj (Cernigoj et al., 2006b) reported alike results and pointed out that using surfactant has a huge impact on morphology of the films by producing coarser but well structured granular surface. In conformity with the SEM results, CAT. 1 has higher porosity and roughness than CAT.3 remarkably. It can be assigned to the fact that using $\mathrm{CH}_{3} \mathrm{COOH}$ and $\mathrm{MC}$ in a sol solution simultaneously caused massive lost of material in ultimate films after calcinations and most of the porosities correspond to the vaporized water and carbon dioxide.

\section{Photocatalytic properties of $\mathrm{TiO}_{2}$ thin film}

Fig. 4a and b demonstrates the comparison between photocatalytic activity and specific surface area of CAT.1-4 respectively. Evaluation of the photocatalytic properties of $\mathrm{TiO}_{2}$ nano films during the degradation of $\mathrm{MB}$ reveals that photocatalytic activity of the catalyst increased with mass percent of anatase phase and BET. In fact, anatase phase with a band gap of $3.23 \mathrm{eV}$ diminishes recombination process in the transformation of electrons-holes to the adsorbed species on the surface of the films. Furthermore, MC generates vast porosity and large number of active surface sites whereas photocatalysts reaction takes place. Therefore, among all the samples
CAT.2 which contains MC and has the most mass percent of anatase phase has the utmost photocatalytic activity.

\section{CONCLUSION}

Titania thin films with anatase crystallite sizes of as small as $11 \mathrm{~nm}$ were deposited on soda lime glass substrates in order to enhance their photocatalytic activity.

The phase structure, photocatalytic activity and texture of Titania thin films prepared by sol-gel route were remarkably influenced by the presence of stabilizer and solvent. Since $\mathrm{HNO}_{3}$ is used as a stabilizer, the crystallization of anatase phase and photocatalytic activity was enhanced considerably and the prepared samples showed high surface area of $198 \mathrm{~m}^{2} / \mathrm{g}$. In contrast, the $\mathrm{CH}_{3} \mathrm{COOH}$ not only prevents phase transformation of the $\mathrm{TiO}_{2}$ powders from amorphous to anatase but also decreased sol stability and photocatalytic activity as well and devastated the surface morphology of the thin films. Worth mentioning, $\mathrm{HNO}_{3}$ has much more effect on sol structure than $\mathrm{CH}_{3} \mathrm{COOH}$. In addition, results revealed that although addition of $\mathrm{MC}$ in the sols increased the porosity of the prepared films and consequently photocatalytic activity but ultimate thin films had rougher surface morphologies. Thus, MC showed binary effect on physico-chemical properties of Titania thin films.

\section{ACKNOWLEDGEMENTS}

The support from the Research Institute of Petroleum Industry and Science and Research Branch, IAU, on this research project is gratefully acknowledged.

\section{REFERENCES}

Akyol, A. A.; Yatmaz, H. C.; Bayramoglu, M., (2004). Photocatalytic decolorization of Remazal Red RR in aqueous $\mathrm{ZnO}$ suspensions. Appl. Catal. B: Environ., 54 (1), 19-24 (6 pages).

Babel, S.; Opiso, E. M., (2007). Removal of Cr from synthetic wastewater by sorption into volcanic ash soil. Int. J. Environ. Sci. Tech., 4 (1), 99-107 (9 Pages).

Bu, S. J.; Jin, Z. G.; Liu, X. X.; Yang, L. R.; Cheng, Z. J., (2005). Synthesis of TiO2 porous thin films by polyethylene glycol templating and chemistry of the Process. J. Eur. Ceram. Soc., 25 (5), 673-679 (7 pages).

Cernigoj, U.; Stangar, U. L.; Trebse P.; Krasovec, U. O.; Gross, S., (2006a). Photocatalytically active TiO2 thin films produced by surfactant-assisted sol-gel processing. Thin Solid Films, 495 (1-2), 327-332 (6 pages). 
Cernigoj, U.; Stangar, U. L.; Trebse, P.; Ribic, P. R., (2006b). Comparison of different characteristic of TiO2- films and their photocatalytic properties. Acta. Chim. Slov., 53 (1), 29-35 (7 pages)

Collins-Martinez, V.; Ortiz, A. L.; Elguezabal, A. A., (2007). Influence of the anatase/Rutile ratio on the $\mathrm{TiO} 2$ photocatalytic activity for the photodegradation of light hydrocarbons. Int. J. Chem. React. Eng., 5 (Article A 92).

Gan, W. Y.; Lee, M. W.; Amal, R.; Zhao, H.; Chiang, K., (2008). Photoelectrocatalytic activity of mesoporous TiO2 films prepared using the sol-gel method with tri-block copolymer as structure directing agent. J. Appl. Electrochem., 38 (5), $703-712$ (10 pages).

Giri, R. R.; Ozaki, H.; Ota, S.; Takanami, R.; Taniguchi, S., (2010). Degradation of common pharmaceuticals and personal care products in mixed solutions by advanced oxidation techniques. Int. J. Environ. Sci. Tech., 7 (2), 251 260 (10 Pages).

Guo, B.; Liu, Z.; Hong, L.; Jiang, H.; Lee, J. Y., (2005). Photocatalytic effect of the sol-gel derived nanoporous $\mathrm{TiO} 2$ transparent thin films. Thin Solid Films., 479 (1-2), 310315 (6 pages)

Habibi, M. H.; Esfahani, M. N.; Egerton, T. A., (2007). Photochemical characterization and photocatalytic properties of a nanostructure composite TiO2 Film. Int. J. Photoenergy, (Article ID 13653).

Hidalgo, M. C.; Sakthivel, S.; Bahnemann, D., (2004). Highly photoactive and stable $\mathrm{TiO} 2$ coating on sintered glass. Appl. Catal. A-Gen, 277 (1-2), 183-189 (7 pages)

Hosseini, S. N.; Borghei, S. M.; Vossoughi, M.; Taghavinia, N., (2007). Immobilization of $\mathrm{TiO} 2$ on perlite granules for photocatalytic degradation of phenol. Appl. Catal. BEnviron., 74 (1-2), 53-62 (10 pages).

$\mathrm{Hu}$, Y.; Yuan, C., (2005). Low-temperature preparation of photocatalytic $\mathrm{TiO} 2$ thin films from anatase sols. J. Cryst. Growth, 274 (3-4), 563-568 (6 pages)

Hussain, S. T.; Siddaqa, A., (2011). Iron and chromium doped titanium dioxide nanotubes for the degradation of environmental and industrial pollutants. Int. J. Environ. Sci. Tech., 8 (2), 351-362 (12 Pages).

JCPDS Powder Diffraction File, (1980). Card 21-1272, 211276, 29-1360. Swarthmore, PA: JCPDS, International Center for Diffraction Data

Jin-sheng, L.; Jun-ping, M.; Guang-chuan, L.; Yan-wen, F.; Yan, D., (2006). Preparation and photocatalytic activity of composite films containing clustered $\mathrm{TiO} 2$ particles and mineral tourmaline powders. Trans. Nonferr. Metal Soc., 16 (2), 542-546 (5 pages).

Kanna, M.; Wongnawa, S., (2008). Mixed amorphous and nanocrystalline $\mathrm{TiO} 2$ powders prepared by sol-gel method: Characterization and photocatalytic study. Mater. Chem. Phys., 110 (1), 166-175 (10 pages).

Keshmiri, M.; Mohseni, M.; Troczynski, T., (2004). Development of novel TiO2-sol-gel-derived composite and its photocatalytic activities for trichloroethylene oxidation. Appl. Catal. B-Environ., 53 (4), 209-219 (11 pages).

Mahshid, S.; Askari, M.; Ghamsari, M. S., (2007). Synthesis of $\mathrm{TiO} 2$ nanoparticles by hydrolysis and peptization of titanium isopropoxide solution. J. Mater. Proc. Tech., 189 (1-3), 296-300 (5 pages).
Medina-Valtierra, J.; Campos-Reyna, S. J.; Frausto-Reyes, C.; Calixto, S.; Ramirez-Ortiz, J., (2007). Self-Cleaning test of doped anatase-coated glass plates. Int. J. Chem. React. Eng., 5 (Article A101).

Mills, A.; Hill, G.; Bhopal, S.; Parkin, I, P.; O,Neil, S, A., (2003). Thick titanium dioxide films for semiconductor photocatalysis., J. Photochem. Photobio. A., 160 (3), 185194 (10 pages).

Ming-fang, X.; Shan, L. ; Xin-man, C. ; Yan-zhi, P., (2006). Studies on characteristics of nanostructure of N-TiO2 thin films and photo-bactericidal action. J. Zhejiang Uni. Sci. B., 7 (7), 586-590 (5 pages).

Negishi, N; Takeuchi, K., (2001). Preparation of TiO2 thin film photocatalyst by dip coating using a highly viscous solvent. J. Sol-Gel Sci. Tech., 22 (1-2), 23 - 31 (9 pages).

Samarghandi, M, R.; Nouri, J.; Mesdaghinia, A, R.; Mahvi, A, H., Nasseri, S.; Vaezi, F., (2007). Efficiency removal of phenol, lead and cadmium by means of UV/TiO2/H2O2 processes. Int. J. Environ. Sci. Tech., 4 (1), 19-25 (7 pages).

Sankapal, B. R.; Lux-Steiner, M. C.; Ennaoui, A., (2005). Synthesis and characterization of anatase-TiO2 thin films. Appl. Surf. Sci., 239 (2), 165- 170 (6 pages).

Sreemany, M.; Sen, S., (2007). Influence of calcinations ambient and film thickness on the optical and structural properties of sol-gel TiO2 thin films. Mater. Res. Bull., 42 (1), 177-189 (13 pages).

Terabe, K.; Kato, K.; Miyazaki, H.; Yamaguchi, S.; Imai, A.; Lguchi, Y., (1994). Microstructure and crystallization behaviour of $\mathrm{TiO} 2$ precursor prepared by the sol-gel method using metal alkoxide. J. Mater. Sci., 29 (6), 1617-1622 (6 pages).

Tobaldi, D. M.; Tucci, A.; Camera- Roda, G.; Baldi, G.; Esposito, L., (2008). Photocatalytic activity for exposed building materials. J. Eur. ceramic Soc., 28 (14), 2645-2652 (8 pages).

Verma, A.; Samanta, S. B.; Bakhshi, A. K.; Agnihotry, S. A., (2005). Effect of stabilizer on structural, optical and electrochemical properties of sol-gel derived spin coated TiO2 films. Sol. Energ. Mater. Solar Cells., 88 (1), 47-64 (8 pages).

Vilhunen, S. H.; Sillanpaa, M. E. I., (2009). Atomic layer deposited (ALD) TiO2 and $\mathrm{TiO} 2-\mathrm{x}-\mathrm{Nx}$ thin film photocatalysts in salicylic acid decomposition. Water Sci. Tech., 60 (1), 2471 - 2475 (5 pages).

Vilhunen, S.; Bosund, M.; Kaariainen, M. L.; Cameron, D.; Sillanpaa, M., (2008). Atomic layer deposited TiO2 films in photodegradation aqueous salicylic acid. Sep. Pur. Tech., 66 (1), 130-134 (7 pages).

Wang, K. H.; Tsai, H. H.; Hsieh, Y. H., (1998). The kinetic of photocatalytic degradation of trichloroethylene in gas phase over TiO2 supported on glass bead. Appl. Catal. B-Environ., 17 (4), 313-320 (8 pages).

Wang, Y. Q.; Yu, X. J.; Sun, D. Z., (2007). Synthesis, Characterization, and photocatalytic activity of $\mathrm{TiO} 2-\mathrm{xNx}$ nanocatalyst. J. Hazard. Mater., 144 (1-2), 328-333 (6 pages).

Wold, A., (1993). Photocatalytic Properties of titanium dioxide(TiO2). Chem. Mater., 5 (3), 280-283 (4 pages).

Yang, Yu.; Guo, Y.; Hu, Ch.; Wang, Y.; Wang, E., (2004). Preparation of surface modifications of mesoporous titania with mono substituted keggin units and their catalytic 
performance for organochlorine pesticide and dyes under UV irradiation. Appl. Catal. A-Gen., 273 (1-2), 201-210 (8 pages).

Yogi, C.; Kojima, K.; Wada, N.; Tokumoto, H.; Takai, T.; Mizoguchi, T; Tamiaki, H., (2008). Photocatalytic degradation of Methylene blue by $\mathrm{TiO} 2$ film and Au particlesTiO2 composite film. Thin Solid Films, 516 (17), 58815884 (4 pages).

Yu, J.; Yu, J. C.; Leung, M. K. P.; Ho, W.; Cheng, B.; Zhao, X.; Zhao, J., (2003). Effects of acidic and basic hydrolysis catalyst on the photocatalytic activity and microstructures of bimodal mesoporous titania. J. Catal., 217 (1), 69-78 (10 pages).

Zhu, T.; Li, J.; Jin, Y.; Liang, Y.; Ma, (2008). Decomposition of benzene by non-thermal plasma processing: Photocatalyst and ozone effect. Int. J. Environ. Sci. Tech., 5 (3), 375-384 (10 pages).

Zhu, T.; Li, J.; Jin, Y. Q.; Liang, Y. H.; Ma, G. D., (2009). Gaseous phase benzene decomposition by non-thermal plasma coupled with nano titania catalyst. Int. J. Environ. Sci. Tech., 6 (1), 141-148 (8 pages).

\section{AUTHOR (S) BIOSKETCHES}

Mastali Khan Tehrani, F., M.Sc., Department of Materials Engineering, Science and Research Branch, Islamic Azad University, Tehran, P. O. Box: 1477893855, Iran. Email: farahnaz.tehrani@yahoo.com

Rashidzadeh, M., Ph.D., Catalysis Research Center, Research Institute of Petroleum Industry, Tehran, P. O. Box: 1485733111, Iran. Email: rashidzadehm@ripi.ir

Nemati, A., Ph.D., Department of Materials Science and Engineering, Sharif University of Technology, Tehran, P. O. Box: 113659466, Iran. Email: nemati@sharif.edu

Irandoukht, A., Ph.D., Catalysis Research Center, Research Institute of Petroleum Industry, Tehran, P. O. Box: 1485733111, Iran. Email: irandoukhta@ripi.ir

Faridnia, B., M.Sc., Catalysis Research Center, Research Institute of Petroleum Industry, Tehran, P. O. Box: 1485733111, Iran. Email: bita_faridnia@yahoo.com

\section{How to cite this article: (Harvard style)}

Mastali Khan Tehrani, F., Rashidzadeh, M., Nemati, A., Irandoukht, A., Faridnia, B., (2011). Characterization and photocatalytic activities of nanosized titanium dioxide thin films. Int. J. Environ. Sci. Tech., 8 (3), 545-552. 